\title{
Only the Wearer Knows Where the Shoe Pinches? Deontics and Epistemics in Discussions of Health and Well-being in Participatory Workplace Settings
}

Wåhlin-Jacobsen, Christian Dyrlund; Abildgaard, Johan Simonsen

Document Version

Accepted author manuscript

Published in:

Discourse and Communication

DOI:

$10.1177 / 1750481319876768$

Publication date:

2020

License

Unspecified

Citation for published version (APA):

Wåhlin-Jacobsen, C. D., \& Abildgaard, J. S. (2020). Only the Wearer Knows Where the Shoe Pinches? Deontics and Epistemics in Discussions of Health and Well-being in Participatory Workplace Settings. Discourse and Communication, 14(1), 44-64. https://doi.org/10.1177/1750481319876768

Link to publication in CBS Research Portal

\section{General rights}

Copyright and moral rights for the publications made accessible in the public portal are retained by the authors and/or other copyright owners and it is a condition of accessing publications that users recognise and abide by the legal requirements associated with these rights.

\section{Take down policy}

If you believe that this document breaches copyright please contact us (research.lib@cbs.dk) providing details, and we will remove access to the work immediately and investigate your claim. 


\section{Only the Wearer Knows Where the Shoe Pinches? Deontics and Epistemics in Discussions of Health and Well-being in Participatory Workplace Settings Christian Dyrlund Wåhlin-Jacobsen and Johan Simonsen Abildgaard}

Journal article (Accepted manuscript*)

\section{Please cite this article as:}

Wåhlin-Jacobsen, C. D., \& Abildgaard, J. S. (20२०). Only the Wearer Knows Where the Shoe Pinches? Deontics and Epistemics in Discussions of Health and Well-being in Participatory Workplace Settings. Discourse and Communication, 14(1), 44-64. https://doi.org/10.1177/1750481319876768

\section{DOl: https://doi.org/10.1177/1750481319876768}

Copyright (C) The Author(s) २०19. Reprinted by permission of SAGE Publications.

* This version of the article has been accepted for publication and undergone full peer review but has not been through the copyediting, typesetting, pagination and proofreading process, which may lead to differences between this version and the publisher's final version AKA Version of Record. 
Paper for DISCOURSE \& COMMUNICATION

Only the wearer knows where the shoe pinches? Deontics and epistemics in discussions of health and well-being in participatory workplace settings

Christian Dyrlund Wåhlin-Jacobsen*a,b ${ }^{*}$ Johan Simonsen Abildgaard ${ }^{\mathrm{a}}$

${ }^{a}$ National Research Centre for the Working Environment, Copenhagen, Denmark

${ }^{b}$ Department of Organization, Copenhagen Business School, Denmark

Version 3, July $12^{\text {th }}, 2019$

*: Corresponding author. Contact information:

Institutional mail address: National Research Centre for the Working Environment, Lers $\varnothing$ Parkallé 105, 2100 Copenhagen, Denmark

Private mail address: Harsdorffsvej 1B, 2.tv, 1874 Frederiksberg C, Denmark

Email address: $\quad$ cdj@nfa.dk

Telephone: $\quad$ +4530 $\quad$ + $\quad 257953$

Coauthor's email address: jss@nfa.dk

Short title: Deontics and epistemics in workplace participatory settings

Word count: 9.845 (including this page) 


\begin{abstract}
In participatory activities in the workplace, employees are invited to raise problems and suggest improvements to the management. Although it is widely acknowledged that employees rarely control decisions in these settings, little is known about the interactional resources that employees and managers draw upon when negotiating consensus about which initiatives to pursue in the future. We analyse interactions from participatory meetings in an industrial setting in relation to the topic of work shoes, showing how the participants orient to both their relative deontic rights (e.g., who can suggest and decide on initiatives) and epistemic rights (e.g., who can define a situation as problematic and assert what can be done about it). The analysis suggests that besides their low deontic status, employees' fragile epistemic status constitutes an important but overlooked challenge to achieving improved working conditions through the participatory activities.
\end{abstract}

\title{
Keywords
}

Conversation analysis, epistemics, deontics, participation, workplace health, safety and well-being, problem and solution work. 
Christian Dyrlund Wåhlin-Jacobsen, $\mathrm{PhD}$, is a researcher at the National Research Centre for the Working Environment in Denmark. In his doctoral work at Copenhagen Business School, he studied the role of interaction in participatory intervention activities, focusing on how decisions are made on the basis of employees' suggestions, how employees decide to assume responsibility for action plans, and the line manager's role in relation to employee voice. He holds an MSc in psychology from the University of Copenhagen.

Johan Simonsen Abildgaard, $\mathrm{PhD}$, is an organizational psychologist and senior researcher at the National Research Centre for the Working Environment in Denmark. He has been involved in the evaluation of several large-scale work environment intervention projects and his focus lies between post-structuralist organization theory and more traditional occupational health-oriented work environment studies within psychology. His topics of research include how working conditions are conceptualized and measured, organizational change as a challenge and planned effort, and mixedmethod evaluation of organizational-level work environment interventions. 


\section{Introduction}

In recent years, a shift has occurred in relation to how workplace participation is conducted in many organizations: while representational and union-based forms of participation used to be the norm in many countries, an increasing number of organizations have implemented regular activities in which employees are invited to voice problems related to work or suggestions for changing existing work practices directly to the managers (Busck et al., 2010). In the EU, for example, almost half of the participating employees in a recent survey study reported frequently being involved in deciding improvements of the work organisation or work processes (Parent-Thirion et al., 2017). Typically, these participatory activities are inspired by practices adopted from the field of human resource management (Heery, 2015) and consist of meetings or talks among employees and their managers (Freeman, 2007; Kersley et al., 2005).

However, some have argued that the increasing reliance on direct forms of participation constitutes a form of sham (Markey and Knudsen, 2014), since in practice, both the overall participatory schemes and the concrete activities they comprise are typically controlled by the management and do not necessarily provide employees with the ability to control decisions, or even with increased decision authority (Hardy and Leiba-O'Sullivan, 1998; Johnstone and Ackers, 2015). As a result, it has been questioned whether direct participation in its most common forms allow employees to secure their health and well-being in the long run (Busck et al., 2010).

The criticism of direct participation implies that since the outcomes of participatory activities are ultimately out of the employees' control, the way they engage in the activities holds little practical impact. However, the actual interactions between employees and managers in participatory settings have so far received little research attention (Garner, 2013). Thus, this study aims to contribute to our understanding of participatory activities in the workplace by describing important features of how interaction in these settings is organized. More specifically, we address 
the research questions: how do the participants' orientations to their relative deontic and epistemic rights in the setting (such as the rights to make decisions or make claims about a problem) shape the outcomes of participatory activities in the workplace?

In recent years, epistemics and deontics have been the subject of a growing number of studies in the conversation analytic (CA) tradition, both in the workplace and in other settings (Stevanovic and Peräkylä, 2014; Stevanovic and Svennevig, 2015) ${ }^{\mathrm{i}}$. The CA approach focuses on how the trajectory of an interaction develops on a turn-by-turn basis as a joint production, based on the participants' visible orientations. On this basis, CA studies have made a number of contributions to the understanding of organizational discourse, including highlighting how organizational features such as hierarchy, though often taken as given, are in practice talked into being (Asmuß and Svennevig, 2009; Boden, 1994). In this study, we apply CA in an analysis of audio recordings of participatory meetings in a Danish manufacturing context. Thereby, we aim to demonstrate how the

outcomes of participatory activities are not only shaped by circumstances external to the interaction, but also very much by the negotiations that take place between employees and managers in the setting.

\section{Direct participation and power}

In the organizational participation literature, discussions of the power differences between employees and the management have featured prominently (Busck et al., 2010; Donaghey et al., 2011; Heery, 2015). However, the focus has predominantly been on structural understandings of power, which frame the management as able to exercise control over the employees due to the ability to determine pay or working conditions, and ultimately hire or fire. For example, in relation to the shift towards direct participation, a topical shift has also occurred from issues such as pay, work hours or recruitment practices towards local, daily work, including health, safety and well- 
being matters (Busck et al., 2010; Harley, 2014; Nielsen et al., 2010). While it has been argued that direct participation is better suited than representative participation for addressing the often diverse problems and concerns that employees have in specialized workplaces (Schuler and Namioka, 1993), the change towards direct participation has also been described as a result of “mainstreaming” (Hasle et al., 2016) whereby participation is increasingly framed as a strategy for managing certain issues from a technical approach and less as a means to democratize decisions in the workplace (Heery, 2015). The notion that the influence available to employees through participatory activities is controlled by the management at an overall level is also promoted by the escalator model of participation (Marchington and Wilkinson, 2005), which suggests that participatory schemes can be meaningfully categorized according to whether employees are merely informed of changes in the workplace (the first step), are able to communicate with managers about the changes, are consulted, or are allowed to co-determine or control decisions (the ultimate step). However, the model does not address the possibility that the employees' degree of influence might depend on the situation or issue, and neither does it consider the employees' strategies for influencing their situation.

In addition to the decision-making rights accorded to the employees, it has been argued that it is important for employees in participatory settings to hold relevant information, which can empower them by putting them in a "better position to make or influence decisions to maintain or improve performance” (Appelbaum et al., 1999: 240; see also Harley, 1999). Akkerman and colleagues state that "without information, employees cannot really participate" (2015: 15). However, the tendency has been to view relevant information as a resource that is controlled by the management (Appelbaum et al., 1999; Hardy and Leiba-O’Sullivan, 1998), and thus another extension of the structural understanding of power outlined above. In addition, information is often viewed as an object of sorts that managers should transmit to their employees, and where 
participation similarly provides employees an opportunity to pass information back to the management (e.g., Detert and Burris, 2007).

The understanding of information as a resource and an object is problematic because it overlooks the inherent indexicality of information and the active meaning-making processes that are crucial to communication (Axley, 1984). For example, it has been shown that what "counts" as information in relation to situated organizational decision-making is not given a priori, but rather a subject of negotiation within the interaction, for example in relation to what constitutes a problem or a relevant solution (Boden, 1994; Cooren, 2007; Samra-Fredericks, 2010). In contrast to how power is typically conceptualized in the participation literature, a pragmatically oriented interactional perspective holds that power does not shape the interaction from without, but must be actively and conjointly enacted in the setting. For example, Hutchby describes power as "a set of potentials which, while always present, can be variably exercised, resisted, shifted around and struggled over by social agents" (Hutchby, 1996: 495). Understood this way, power and authority is instantiated in specific interactional asymmetries.

\section{Asymmetries in interaction: the deontic and epistemic orders of interaction}

While asymmetries in interaction, such as the differential rights to ask questions or control the interactional agenda in institutional interaction, have been studied since the 1970s and 80s, deontics has proliferated as a topic in its own right through the substantial theoretical development that has occurred in recent years in relation to research on such topics as offers and requests (Clayman and Heritage, 2014; Curl and Drew, 2008), directives (Craven and Potter, 2010) and threats (Hepburn and Potter, 2011). The deontic order concerns how speakers display public orientations to their socio-moral rights and obligations in relation to requesting, deciding or performing actions, as well 
as to the rights of other interlocutors or non-present third parties. Such displays index the speakers' deontic stance relative to the other participants, whereby the speaker may implicitly or explicitly claim a privileged right to direct others' actions, or to have their actions directed. These stances are oriented to by the interlocutors as being rooted in a certain deontic status, which reflects the speakers overall position in the domain relative to others. The gradient between the participants' statuses is for example indexed in the degree of entitlement implied by the speaker to have others act as desired, or whether the speaker orients to contingencies in the recipients' ability to perform the requested/directed action or not (Craven and Potter, 2010).

In many cases, speakers' deontic stances are relatively congruent with their statuses, so that organization members who hold a higher formal position in the organizational hierarchy, for example, would also display a high degree of entitlement to having their requests followed by subordinates. However, this is not always the case: superiors may take downgraded deontic stances in order to "do" egalitarian leadership in interaction (Svennevig, 2011), and, as Stevanovic and Peräkylä argue, "speakers with low authority sometimes can try to inflate their authority with more assertive directives" (2014: 91). However, without the deontic status to back them up, such incongruently strong stances run the risk of being challenged by the other participants. In relation to participatory activities, we would expect the deontic order to be attended to by the participants when negotiating the employees' rights to present suggestions for future initiatives, or deciding whether to implement a given initiative, for example.

In addition to the deontic order, interlocutors orient to their relative rights and obligations to hold and present information, or epistemics (Heritage, 2013; Stivers et al., 2011). Fundamental to socioepistemic analyses of interaction is the observation that in many situations, interlocutors will have different degrees of access to some epistemic domain, and they visibly orient to their rights to claim and present knowledge about this domain in the interaction. Thus, similar to the deontic 
order, each interlocutor can be said to hold an epistemic status which can be claimed or indexed through the deontic stances they take: for example, while initiating a description with "I think" typically is taken to mark a downgraded stance, "certainly" instead typically marks an upgraded stance. Areas where speakers are usually oriented to as having a superior epistemic status, or authority (Heritage and Raymond, 2005), are typically in relation to their own thoughts, feelings, sensations or experiences (Heritage, 2012; Landmark et al., 2015). In addition, epistemic authority can also be claimed in relation to various topics on the basis of expertise or other forms of access associated with membership of social categories, such as "doctor" (Raymond and Heritage, 2006).

However, struggles can arise between speakers about their relative epistemic statuses (Mondada, 2013), for example when experience- and expertise-based forms of authority are in conflict (Heritage, 2013). Furthermore, like for the deontic order, claiming too high a status through one's stance leads to a risk of others addressing the incongruence in the interaction and the speaker being held accountable (Heritage and Raymond, 2005; Mondada, 2013; Raymond and Heritage, 2006). In this way, speakers "patrol and defend" their relative statuses in the interaction (Goffman, 1971, cited in Heritage and Raymond, 2005: 34). In relation to participatory workplace settings, we would thus expect the epistemic order to be especially relevant in relation to the reports of events or experiences that the participants provide when discussing their current working conditions or evaluating suggested initiatives for improving employee health, safety and well-being, for example. In discussions of what constitutes problems in the workplace and who are responsible for them, participants orient to both the epistemic and deontic orders and the potential interplays and ambiguities between them (Angouri and Bargiela-Chiappini, 2011). For example, Stevanovic and Peräkylä (2014) show how speakers can invoke their epistemic authority about some matter to defend their deontic status when it is potentially challenged. However, they also acknowledge that when one's deontic status is defended through references to one's epistemic status, one might find 
oneself overruled by others with an even higher deontic status, who might, for example, announce a decision without orienting to the knowledge held by those with a lower deontic status. Thus, in some cases, a more detailed understanding of the interaction can be reached by considering such interplays.

\section{Methods}

\section{The CA approach}

CA is considered to have been founded by Sacks, who presented what became the basic tenets of this approach during his lectures in the 1960s and 1970s (Sacks, 1992). CA is fundamentally concerned with how social interaction is organized, how various actions are produced and recognized, and how the parties manage the various problems that can arise, such as ambiguity, misunderstanding or disagreement. While Sacks' ideas were initially developed mainly by his close colleagues, CA has since grown into a research field covering a wide range of interactional phenomena (Stivers and Sidnell, 2012).

A defining feature of the CA approach is basing the analysis on the interlocutors' visible concerns and orientations. Here, CA studies derive benefit from a basic feature of all interaction: since no expression (verbal or otherwise) can fully provide for its own interpretation (i.e., they are indexical), the main way speakers can know whether an utterance, for example, has been understood as intended is by observing the recipient's response. If so, the speakers are said to have coordinated intersubjective understanding. If, however, a response is provided that is not fitted to the action that the original expression was meant to index, various means are available to the speaker to try and repair the lapse of intersubjectivity (Kitzinger, 2012). This next-turn proof procedure (Sacks et al., 1974) means that analysts can attend to how expressions are interpreted and reacted to in the given situation, and how the interaction progresses as a result. 
One major branch of CA research has addressed interaction in institutional settings, including in the workplace. Although interaction in these settings displays many of the same features as everyday talk (Drew and Heritage, 1992), one characteristic of workplace interaction is how participants often orient to their different role categories, such as manager and employee, and the rights and obligations that are tied to these categories, even when such roles are not topicalized explicitly (Asmuß and Svennevig, 2009; Larsson, 2017). However, as indicated above, these rights and obligations must be enacted locally, and thus, the interactional asymmetries that arise because of how they are enacted are effectively talked into being. In this study, we focus on how asymmetries arise on the basis of the participants' orientations to deontics and epistemics, and how these asymmetries shape the outcomes of discussions in participatory settings.

\section{The data}

The data for this article were collected in connection with a research project in which a series of participatory activities were conducted in Danish manufacturing organizations. Denmark, along with a number of other Scandinavian and Northern European countries, is generally recognized as having a relatively high degree of participation in the workplace (Parent-Thirion et al., 2017), although the manufacturing sector is thought to contain lower degrees of employee involvement than many other sectors (Eurofound, 2013). Thus, the overall context for the data collection can neither be said to be exceptionally favourable or unfavourable to employee participation.

Danish occupational health and safety regulation requires all workplaces to perform regular risk assessments with participation from the employees, which often takes the form of meetings or others forms of direct dialogue with managers. The intervention activities studied here primarily deviated from such meetings through the presence of an external process facilitator, who chaired the meetings according to guidelines set out by the research group. Besides both authors participating in 
the overall research group and as observers in a number of meetings, the first author participated in 22 meetings as a facilitator (though not in the meeting sequences presented in this article).

The meetings were typically attended by 6-10 employees who worked together on a daily basis, either as semi-skilled machine operators or skilled maintenance staff. The employees each participated in three three-hour meetings, whose agendas focused on (1) identifying problematic and positive circumstances in the work environment, (2) developing actions plans for how the local work environment could be improved, and (3) following up on whether these action plans were implemented as expected. Action plans were developed according to a template and subsequently placed on a kaizen board in the participants' work area, allowing the participants to monitor implementation progress (see, for example, von Thiele Schwarz et al., 2017).

In practice, all three meetings featured discussions of both problematic aspects of the work environment and what could be done about them. While initially transcribing and reviewing our data, we noticed how the participants presented various descriptions and evaluations of the work environment as being problematic, along with a number of suggested solutions to these problems ${ }^{\mathrm{ii}}$. The process of negotiating some form of consensus among the participants in relation to the candidate understandings and suggested initiatives often spanned long stretches of conversation. Among approximately 98 hours of audio from 36 meetings which were collected, we here focus discussions in relation to one exemplary topic: work shoes. While the findings we present here could likely be encountered for a number of different health, safety and well-being issues, we focus on work shoes since these were raised as a problem throughout the data and because of how the participants' discussions in relation to this topic illustrate important points about epistemics and deontics in participatory settings. Still, in order to provide a more detailed analysis, we have chosen to select only a few sequences from two meetings for presentation here. 
Though video data could have contributed to a more detailed analysis of how the participants draw on various modalities in their interaction, only audio was recorded due to the data originally being collected as background information for other, less interaction-focused analyses. In developing this analysis, we worked from the audio recordings and transcripts in conjunction, collecting excerpts of interaction where participants discussed work shoes. These excerpts were then analysed following a conversation analytic approach in order to attend to both how understandings are coordinated on a turn-by-turn basis, how the participants orient to the epistemic and deontic orders in their utterances, and how these orientations shape the overall trajectory of the interaction. The excerpts were transcribed using a simplified Jefferson style (Jefferson, 2004, see appendix for legend) and are presented here in their translated form. All names have been changed to ensure participant anonymity.

\section{The meeting setting}

All meetings were held in meeting rooms at the worksite. The facilitator would chair the meetings, following loosely a pre-set agenda. The major part of the interaction in the meetings consisted of discussions among the employees and their manager in relation to health, safety and well-beingrelated aspects of their work or the facilitator interviewing the participants about such topics in order to progress the risk assessment, action planning or follow-up tasks of the meetings. There were no pre-set boundaries regarding which initiatives could be suggested or decided on, but participants had to secure the necessary approvals and funding within their organization; no economic or practical support was provided by the research team. In the meetings, all participants (except the observers) would be seated around the same table in order to facilitate discussions within the group. The names and formal work roles of the interlocutors featured in the excerpts are presented in table 1. 
*** Insert table 1 about here ***

\section{Analysis}

As the upcoming excerpts are rich, the analysis will focus on main points that are specifically relevant for this article. The first three excerpts are taken from a meeting in a plastic packaging company, demonstrating some fundamental aspects of what can be called the participants' "problem work" and "solution work" and how these interrelated activities are shaped by the participants' orientation to deontics and epistemics. The remaining excerpt focuses on more complex aspects of this relationship and is taken from a meeting in a pharmaceutical company. We note that although the participants in the excerpts could be said to engage in the activity of decision-making, our focus here is not on the decisions themselves or the moment where they are formulated or announced (Clifton, 2009) - events which may never actually occur (Huisman, 2001). Instead, we attend to the participants' negotiations of what can be considered a problem, what causes it, what can be done about it and more generally: whose opinion counts in these discussions?

\section{Problem and solution work and their epistemic and deontic foundation}

In excerpts 1 and 2, the participants are sitting around the meeting table and have just finished making notes on paper handouts which they have before them. The handouts contain various symbols representing different aspects of the work environment. Amelia, a process facilitator, is interviewing the employees about which aspects of the work environment they have marked as problematic ("red") or helpful (“"green").

\section{Excerpt 1}

○yes

$(0.6)$

other things?

$(0.6)$ down here

(1.5) 


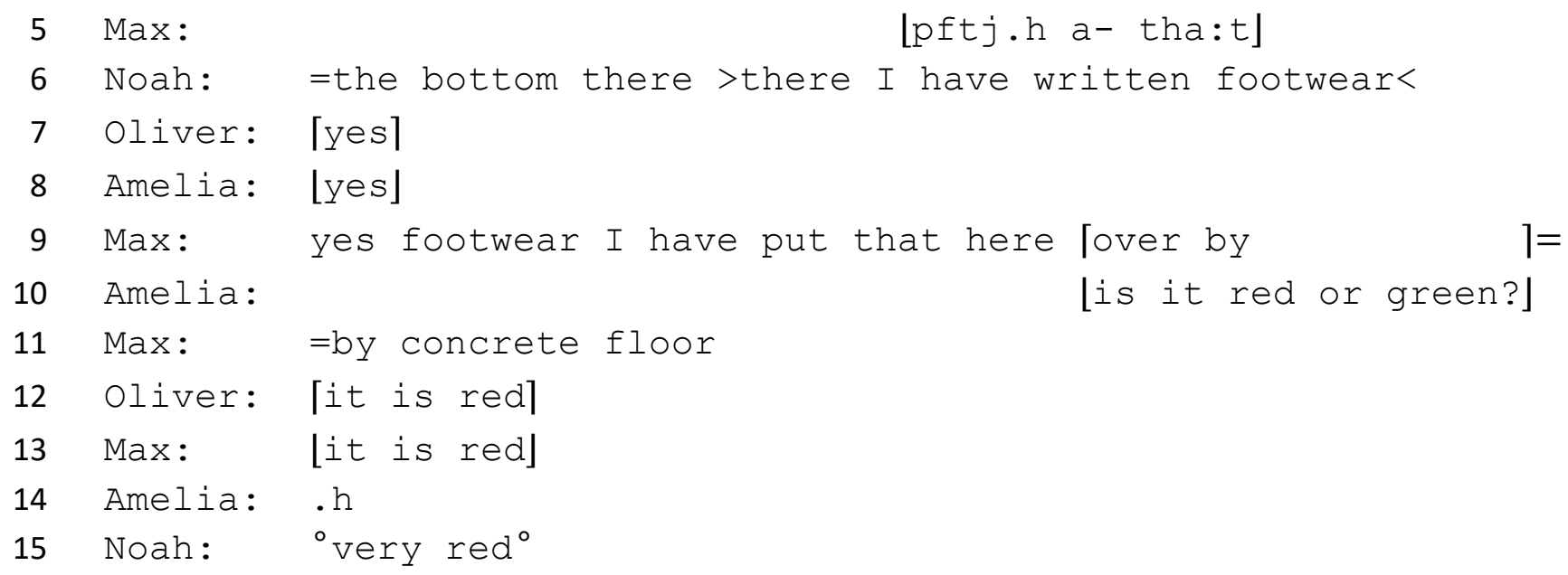

The excerpt begins with Amelia asking the participants to report their markings, mentioning various areas of the handout as examples of topics the employees may have addressed (1.3). One employee, Noah, responds with a report that he has written footwear at "the bottom" of the template (where the category of "bodily" circumstances is one of the featured categories), and two other employees, Oliver and Max, affiliate (Stivers et al., 2011) with Noah's response (1l. 7 and 9), though Max adds that he had marked footwear elsewhere ("by concrete floor"). In partial overlap with Max, Amelia asks if the employees have marked footwear as being "red" or "green", thereby ratifying their response as relevant, and Oliver and Max both answer "red" in overlap, with Noah providing an upgraded evaluation ("very red") shortly after (1.15). We note that several employees respond to Amelia's question, and this shared access to the floor for the employees is characteristic of participative decision-making interactions (Baraldi, 2013). The circumstance that the employees' responses are produced in a minimal, immediate manner suggests that the agreement between the employees' stances is mutually expected - in contrast, a response that was delayed or softened (such as "well, to me...") could have indicated an orientation towards potential disagreement (Pomerantz, 1984). However, the general absence of softeners or pauses here also implies a high epistemic stance for the employees, while Amelia positions herself as not-knowing through her questions. 
As a form of shorthand, we refer to the interactional activity involving the facilitator's questions and the employees' descriptions of "red" circumstances as a form of "problem work" (Francis, 1995) that is oriented towards mutually constructing a formulation of what constitutes health, safety and well-being problems for the employees in their work setting (i.e., the 'states of affairs', Huisman, 2001: 75). Evaluations (such as those made of the shoes) and attributions of problems to certain features of the work environment (such as the concrete floor), as well as affiliative and disaffiliative responses to such utterances, constitute key action elements of this work, which will also surface in the remaining excerpts.

In the next excerpt, which follows immediately after Excerpt 1, the participants' problem work shifts into a related activity which we gloss as "solution work", corresponding to Huisman's point that participants in decision-making episodes orient to building "commitment to particular future states of affairs" (Huisman, 2001: 75). Action aspects of the participants' solution work which feature here are suggestions of candidate solutions, assessments of the viability of these suggestions, assessments of the relative merits of different suggestions, and affiliative and disaffiliative responses towards these assessments.

\section{Excerpt 2}

Amelia: a:nd why is it that?

(1.3)

Oliver: they are not good enough the shoes

Amelia: ¡no? †

Max: $\quad\left\lfloor{ }^{\circ} 0^{\circ}\right\rfloor$

Teddy: twelve hours on a concrete floor then=

Oliver: =yes so: those

$(1.4)$

Max: and maybe one could have soles a little more often Tor insoles or 1

Oliver: [well well well IJ bloody do not believe those shoes I mean you can get some [shoes] 
Teddy :

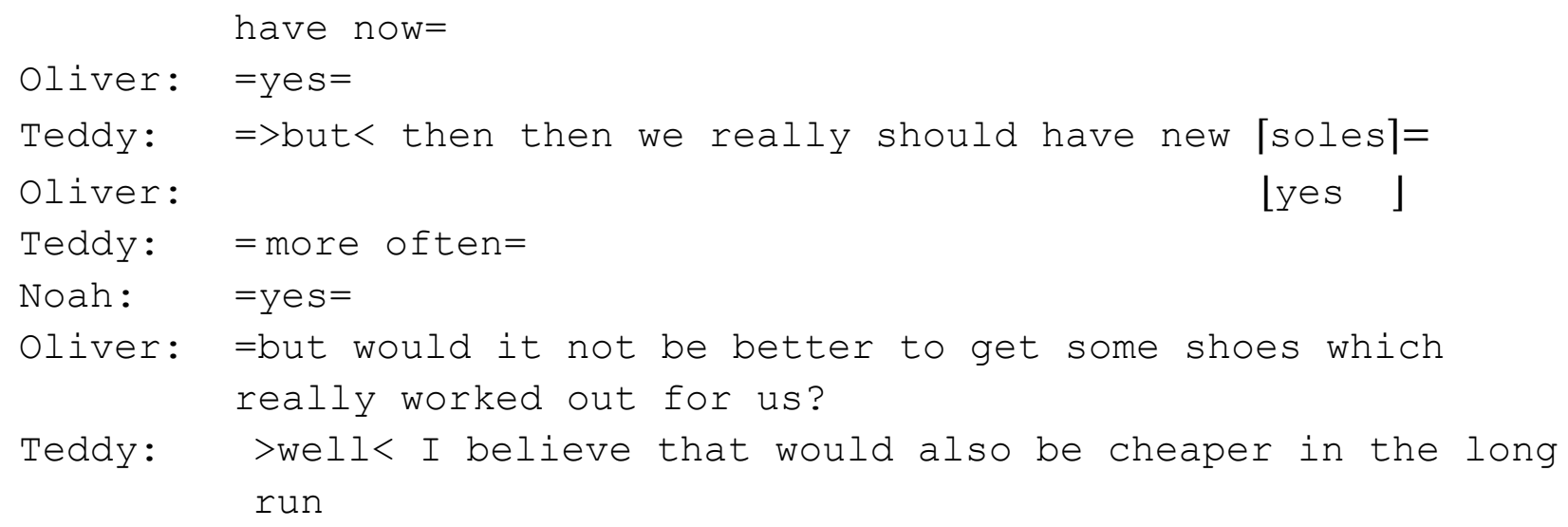

Here, Amelia first asks why the shoes were marked as red, to which Oliver accounts that the shoes are "not good enough", while a fourth employee, Teddy, once again mentions the concrete floor of the production area as potentially contributing to the footwear problem, as well as the employees' 12-hour shifts. The discussion proceeds with Max self-selecting and stating that the employees could perhaps receive new insoles more often (1. 24). It is notable that Max's turn is formatted in a somewhat ambiguous way, presenting an assessment of the chances of having new insoles, but also implying that new insoles could alleviate the problem, and thus making the insoles relevant as a candidate solution (Stevanovic, 2011). If viewed as an assessment, the epistemic domain is made relevant, and Max's use of downgraded terms in his suggestion (i.e. "maybe" and "a little more often", 1. 24) suggests that the prospects of securing an agreement with the management are uncertain. When understood as a suggestion, the deontic aspect is highlighted, indicating that Max is taking a downgraded deontic stance in relation to his team leader, Finn, who is also present and is in a position to potentially facilitate this agreement. Thus, we here see an ambiguity between the epistemic and deontic domains (Stevanovic and Peräkylä, 2014).

Continuing our analysis, we see that Finn does not reply here, as Oliver takes the next turn. The first part of his turn is truncated, but the "well" preface and the first part of a negative assessment ("I don't believe those shoes") marks it as a disaffiliative response towards Max's turn. 
Furthermore, by addressing the quality of the shoes, rather than the prospects of having insoles, Oliver seems to orient towards the suggestion aspect of Max's turn and its adequacy for alleviating the "red" shoes. The rest of Oliver's turn is also truncated, but formatted as the first part of an assertion about other shoes, which, like Max's last turn, can be heard as an implicit suggestion ("I mean you can get some shoes"). We note that the unhedged character of Oliver's partial assessment and his previous negative evaluation of the shoes (1.18) both work to index a high epistemic stance in relation to defining the shoes as the problem.

Teddy's next turn orients to Oliver's turn as another suggestion and also provides a "well”prefaced disaffiliating response, suggesting the premise that the employees may have to keep their current shoes (11. 28-29). After an alignment token from Oliver (1. 30), Teddy affiliates with Max's suggestion of having new insoles. Oliver and Noah both answer "yes" (11. 32, 34), yet Oliver's following question (11. 35-36) strongly projects an acceptance of his argument that getting new shoes would be preferential. Teddy offers a somewhat softened assessment ("well I believe", "that would") which affiliates with Oliver's stance, providing an economical argument for changing the shoes.

In relation to the notion of solution work, we wish to make two points: first, it is not made explicit at this point why the shoes are described as "red" by the employees, although Noah's registration of the issue as a "bodily" problem and Max marking the shoe problem next to "concrete floor" suggests slightly different problem understandings. Similarly, although Max's suggestion (1. $24)$ is topically related to Oliver and Teddy's problem description (11. 18, 21), it does not explicitly address either the quality of the shoes or the concrete floors. However, the lack of consensus around one formulation of the problem does not prevent the participants from engaging in further discussions of potential solutions, as the excerpt demonstrates. Second, Max (11. 24-25) and Teddy (11. 28-29, 37-38) both orient towards the ambiguity surrounding whether getting new shoes would 
be a viable solution, or if some economical argument might be invoked to challenge the suggestion. Thus, though the employees overall take quite strong epistemic stances towards their various problem descriptions, the matter of which solutions are potentially available is less certain and perhaps out of the employees' control. While Finn could either provide his assessment of the prospects of receiving new shoes/insoles, or respond to Max and Teddy's turns as suggestions, Finn's silence leaves it to the employees to instead continue the discussion for now, based on their own assessments of whether getting new shoes is viable.

The next excerpt follows shortly after the first two. Here, we turn to how the participants' differential rights to claim knowledge in relation to different epistemic domains shape the process of negotiating candidate problem and solution constructions. The employees are discussing how footwear problems might influence the well-being of the employees in a wider sense when the employees' manager, Finn, presents an assertion about the work shoes:

\section{Excerpt 3}

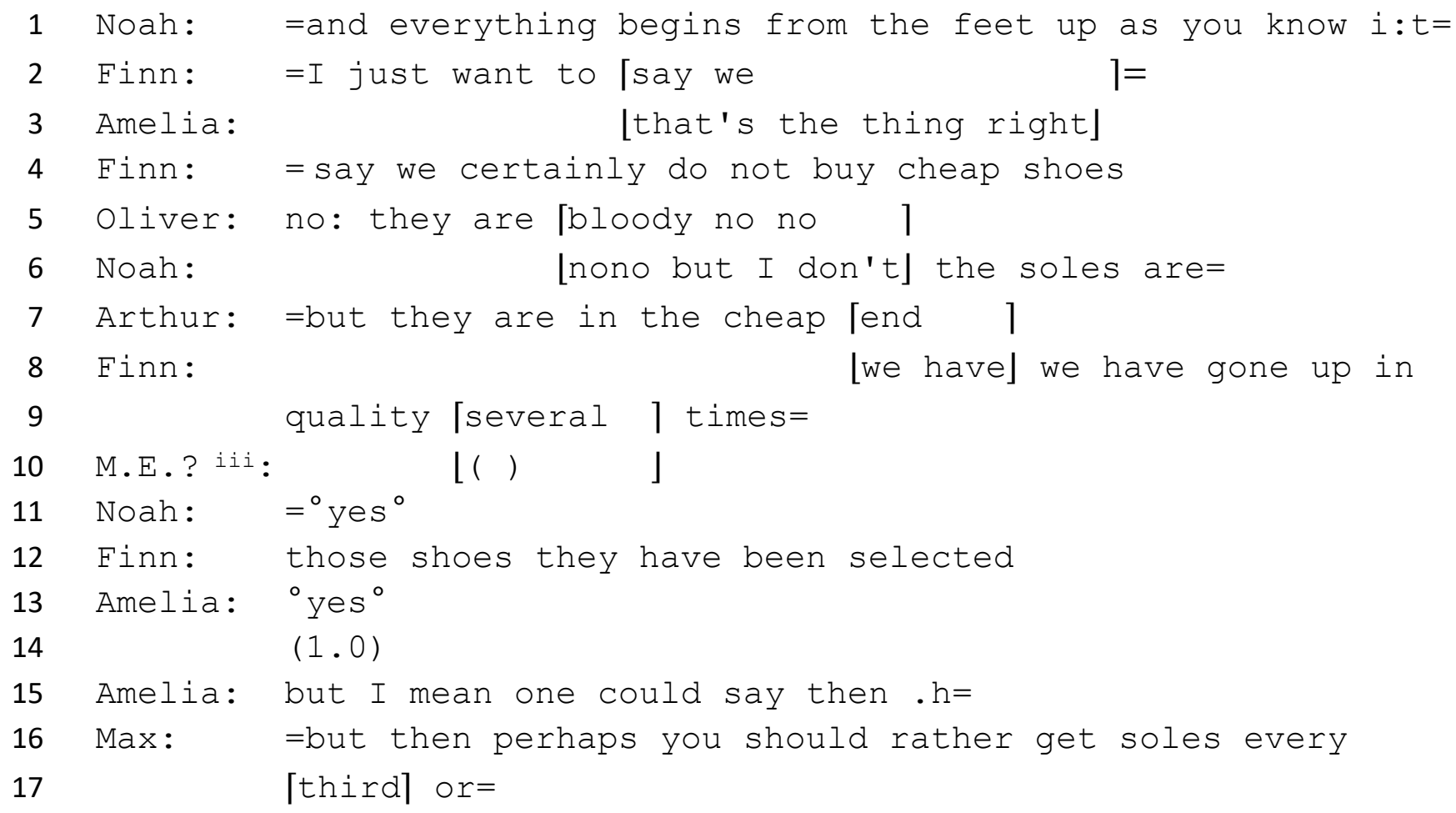


In this excerpt, Finn takes the floor and describes the work shoes currently sourced by the company as being "not cheap". Finn's assertion addresses the employees' candidate problem construction from Excerpt 1 and 2 (voiced by Oliver) that the quality of the shoes is inadequate, but also attends to the "complainability" of the shoes (Schegloff, 2005). Negative evaluations of work shoes or other aspects of their work environment are not necessarily responded to as morally implicative complaints, for example in the form of excuses or rejections. However, as Schegloff writes, interlocutors who are cast as possible agents of complainables sometimes orient towards this aspect of speaker's talk in their own turns, even when the transgressive aspect of their actions is merely alluded to or inferable. Thus, Finn could be said to address the normative implications of the employees' problem work, and specifically the hearable implication that the company's choice of work shoes has been more motivated by cost than concern for the employees. In addition, Finn takes an upgraded epistemic stance ("certainly"); as a middle manager with a long history in the organization, Finn holds privileged knowledge about the price of the work shoes, and this privileged epistemic access is indexed here.

Next, Oliver and Noah indicate agreement with Finn's assertion in overlap (11. 4-5), thereby distancing themselves from the normative position alluded to by Finn, while Arthur recycles Finn's "not cheap shoes" description into shoes from the "cheap end", providing an assessment which does disagreement with Finn. Arthur's assessment is not attended to by Finn, however, who in partial overlap with Arthur reports that the company has "gone up in quality several times". After an alignment token from Noah, Finn asserts in line 12 that the shoes have been "selected", thus again addressing the potential complainability of the shoes. In these turns, Finn's superior epistemic stance is indexed through the direct and minimal way his announcements are presented (Heritage and Raymond, 2005). 
Towards the end of the excerpt, Amelia minimally aligns with Finn. Her next turn (1. 15) comes after a short pause and is prefaced by “but I mean”, both features which indicate that a dispreferred response is upcoming in relation to Finn's assessment. However, her turn is cut short by Max, who repeats his suggestion to change soles more often, to which Finn affiliates. Several points are interesting about these last turns: for one, by focusing on insoles in his suggestion, Max sidesteps the thorny issue of the work shoes' quality as he once again shifts the discussion from problem to solution work. Second, Max's suggestion can be heard as an upshot of Finn's previous utterances (Heritage and Watson, 1979), and it is once again marked with a downgraded stance, this time more clearly in the deontic domain ("perhaps you should rather get", 1. 16), and responded positively to by Finn, who thereby claims entitlement to assess the suggestion.

Overall, the excerpt thus suggests that even without having coordinated consensus around one formulation of the problem, the group is able to work towards a decision on how to formulate its suggestion. This is in line with how Huisman (2001) has described that participants in decisionmaking episodes sometimes fluctuate between building consensus around formulations of the current states of affairs and commitment to future states of affairs. However, we also see that managers' ability to challenge the employees' problem descriptions can work to close off certain potential solutions from being discussed further. In the excerpts, the management is oriented to as holding the deontic status to choose which suggestions to accept and which to refuse, in spite of the "participatory" character of the setting.

\section{Challenging the employees' epistemic stance in areas where they hold primacy}

The management's ability to challenge employees' problem descriptions may not only be based on areas where the management would be expected to hold epistemic primacy, such as economic matters, but also stretch into areas that employees are normally thought to hold privileged access to. 
This is demonstrated in the next excerpt, which is taken from a meeting in a pharmaceutical company. Here, the employees jointly constructed various foot problems as the result of ill-fitting shoes, a complaint they had also voiced outside of the workshop. The employees were required to wear the shoes after a managerial decision that employees could only use certain models of safety shoes from one specific supplier. In the excerpt, the employees' health and safety representative, Beth, is discussing how some non-present members of the management have questioned the employees' problem formulation by claiming that only employees from the present department complain about their shoes, despite all departments having the same selection to choose from. The argument implies an expectation that if the new work shoes were the source of the employees' foot problems, the management would have also received complaints from employees in other departments.

\section{Excerpt 4}

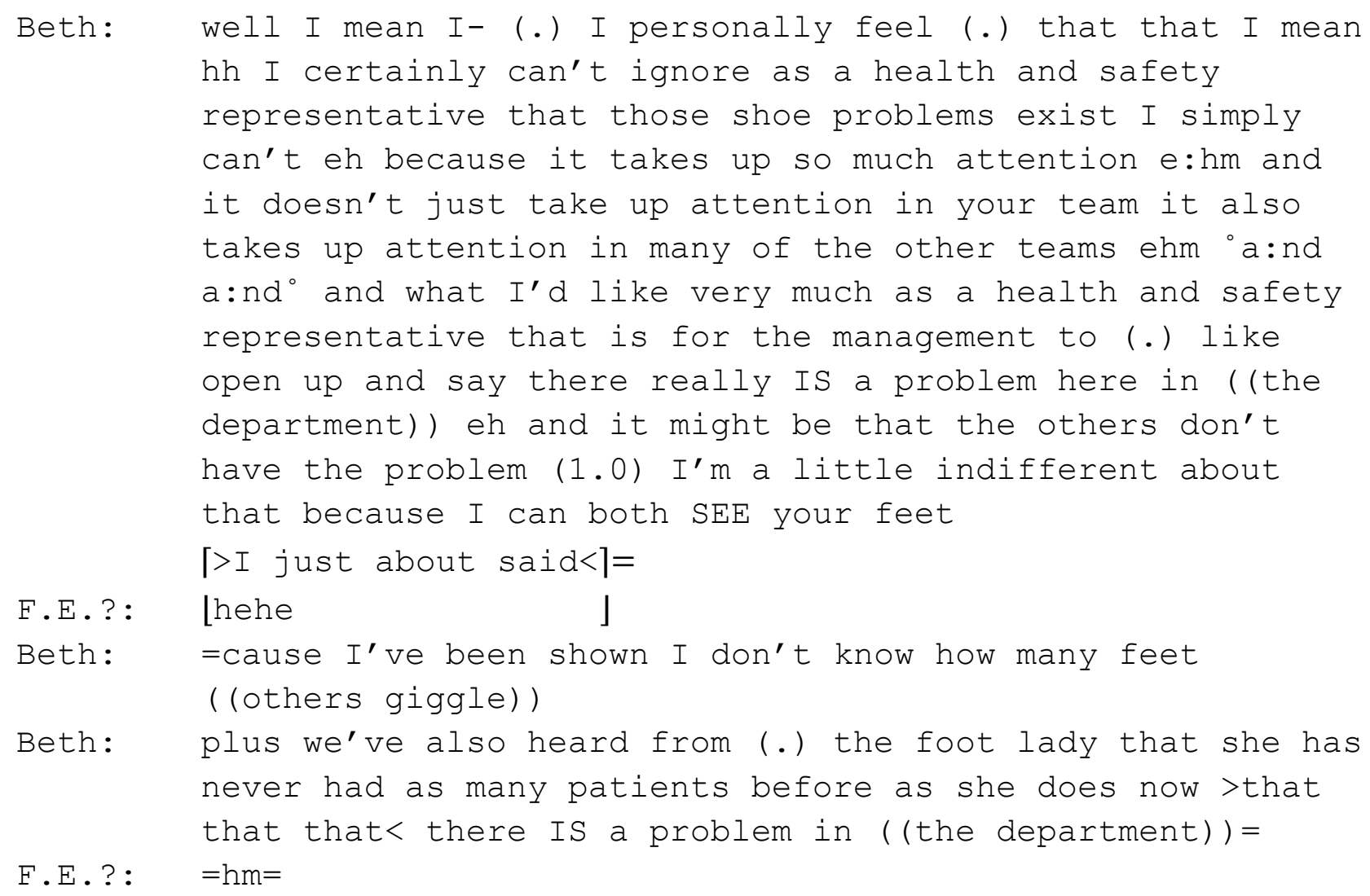




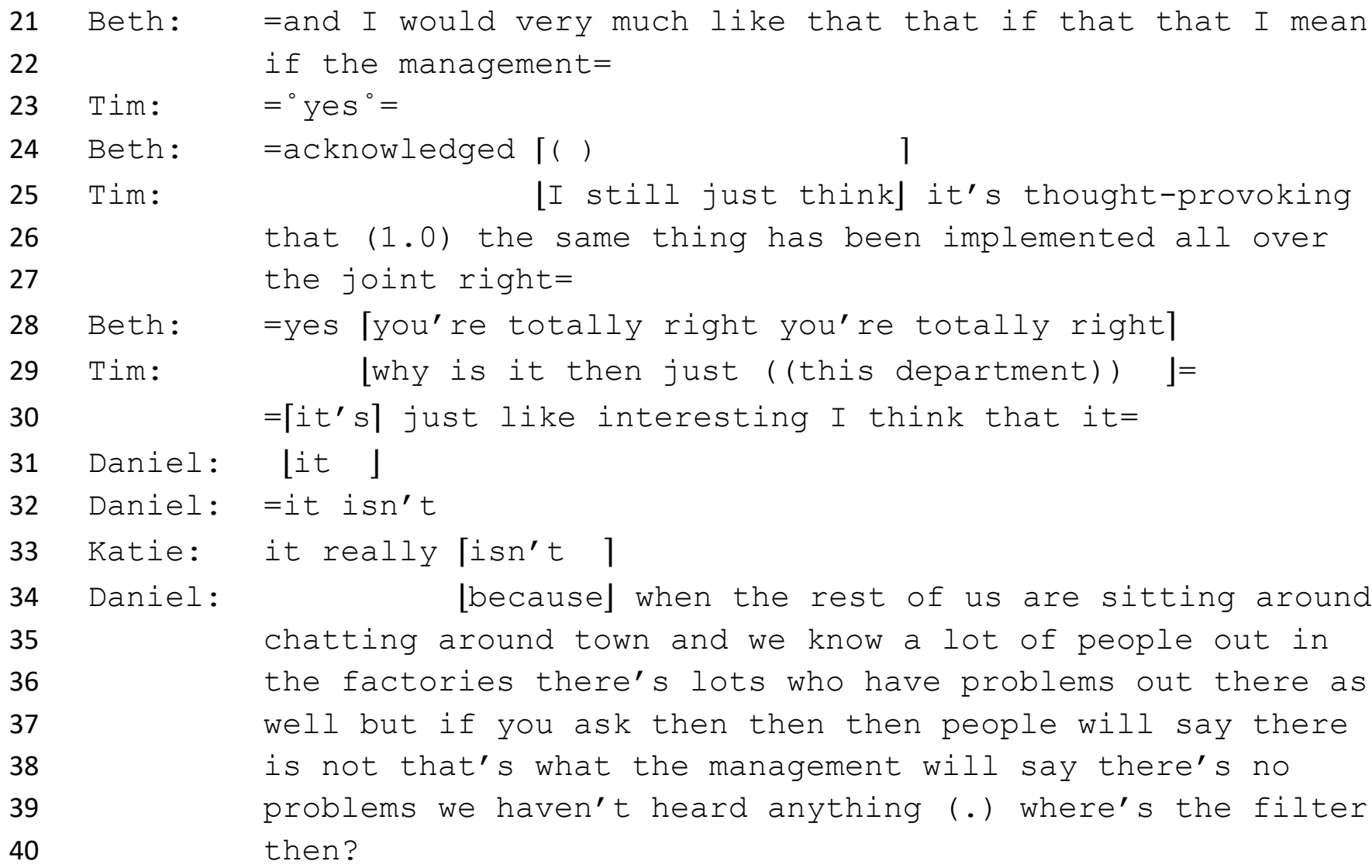

In the excerpt, Beth argues that she cannot ignore "those shoe problems", accounting for her stance by self-categorizing as the employees' elected health and safety representative, and thus suggesting that she holds a form of role-bound obligation to bring up such issues (Jayyusi, 1984). She next reports that the problem "also takes up attention in many of the other teams", thereby doing disagreement with the argument provided by members of the management. Beth next requests that the management acknowledge the employees' problem formulation regarding the shoes, taking a somewhat downgraded deontic stance: for one, the request is marked with low entitlement ("I'd like very much") and accounted for through another reference to her role as health and safety representative (11. 7-8). Furthermore, she orients to the contingency posed by the management's claim that the problem isn't found in other departments (11. 10-11). However, she also challenges the relevance of this contingency by reporting her own experiences with (and thus direct epistemic access to) employees 
showing her their feet $(11.12,15)$, and through a paraphrased report from the "the foot lady", seemingly a professional who employees at the worksite consult about foot problems, but whose job title or organizational affiliation is not accounted for in the recordings. The "foot lady" is thus invoked here as an expert with subject-specific epistemic authority to warrant Beth and the employees' problem formulation.

Beth next seemingly begins reiterating her request that the management acknowledge the employees' complaints, to which Tim, the employees' line manager, aligns (1.23) before starting a turn in overlap with Beth. Here, Tim describes it as "thought-provoking" and "interesting" that while the rules have been implemented "all over the joint" (11. 25-27), complaints or problems are encountered on in their department (11.29-30). Tim thereby affiliates with the claim previously presented by the management, while at the same time providing an account for his lacking affiliation with the employees' problem definition and Beth's requests. By claiming access to the content of Beth's request, but not expressing agreement with Beth's arguments, Tim's utterance projects what can be called a non-decision (Stevanovic, 2012).

In spite of Tim's disaffiliation, Beth expresses alignment in overlap with Tim, suggesting that she knows and accepts Tim's argument as relevant. However, Daniel and Katie disaffiliate with Tim's argument. Daniel then takes a long turn accounting for his disalignment, referencing informal chats with other employees outside of the workplace as the epistemic basis of his counter-claim and posing the question: "where's the filter then?" (1. $39-40)$.

Two overall observations are relevant in relation to this fourth excerpt: first, Beth's requests to "the management" makes a reply from Tim (as a manager) potentially relevant, similar to some of Max and Teddy's utterances in Excerpt 2. However in this case, the request is addressed by the line manager. It can be stipulated that the employees' somewhat 
ambiguous suggestions and requests constitute a practice whereby employees intend to potentially recruit their team leader to take action (for example by raising the matter with other members of the management) while reducing the risk of flat-out rejection that would have been inherent if a more direct suggestion or request been expressed. Second, both Beth and Tim orient to the management as being entitled to decide whether to ratify the employees' problem formulation or not. However, in the excerpt, Tim neither provides an alternative account for the employees' foot problems, nor suggests alternative solutions to sourcing new shoes, indexing a superior deontic status relative to the employees.

\section{Conclusion}

Though a number of studies have focused on power in participatory decision-making, both within the workplace (Hardy and Leiba-O’Sullivan, 1998; Heery, 2015) and elsewhere (Cooke and Kothari, 2001; Farkas, 2013), little research has explored how participants negotiate what can be considered a problem and what they can do about it. Based on a conversation analytic approach, the present study contributes to discussions of power in participation by demonstrating that even at the "micro" level of problem and solution work, the possibilities that employees are ostensibly given for influencing their working conditions in participatory settings might be challenged due to asymmetries in the epistemic and deontic interactional domains. Indeed, both of the teams studied here chose to pursue a somewhat "minimal" solution at a later point (the insoles as opposed to different or additional shoes in the first three excerpts and sourcing different work shoes for the specific team as opposed to a general rollback to using the previous shoe-supplier in the fourth).

The analysis offers several contributions to discussions of workplace participation. For one, we have shown how employees' problem and solution formulations are actively constructed in interaction. This is in contrast to how much of the literature on participation 
tends to take what employees wish to voice as fixed, instead attending to "transmission" problems such as whether this content is actually voiced and whether it is accepted by its targets (Axley, 1984; Hardy and Leiba-O’Sullivan, 1998; Morrison, 2011). Even in relation to a seemingly mundane topic such as work shoes, the analysis showed working towards some degree of consensus around formulations of their current state of affairs and committing to pursue particular future states of affairs involved the presentation and negotiation of various competing problem constructions and candidate solutions, each of which projected somewhat different outcomes for the activities. On the basis of our analysis, it can be suggested that incurring change through participation might prove difficult in cases where the participants' ability to coordinate consensus around one suggested remedial action problems is challenged, for example for circumstances which are not recognized as problems by the management or by some portion of the employees. This could be the case for a substantial portion of potential health and well-being issues in the workplace (Busck et al., 2010).

Second, both epistemics and deontics were shown to play a key role in the participants' problem and solution work. Although concern has been expressed over ascriptions of epistemic status in interactional analyses (e.g., Lindwall et al., 2016), we believe that an analytical orientation to epistemics and deontics is both methodologically viable and highly relevant for elucidating how asymmetries arise in interaction. For example, in the excerpts, epistemic access in relation to certain topics was invoked to support or question various problem formulations for both employees (in relation to private bodily sensations), managers (shoe cost and previous managerial decisions), health and safety representatives (similarities between problems experienced by different groups of employees) and outside experts such as "the shoe lady" (professional assessment of the employees' foot status). In addition, the participants drew upon various inferential practices rooted in epistemics in their argumentation, such as the management's claim to know that the problem 
only occurred in one department in Excerpt 4, or Daniel's reasoning that since the employees knew the problem also existed elsewhere, those cases must not have been taken into account by the management when arguing that the problem only existed in one department.

While relevant and sufficient information has often been named as a prerequisite for employees to effectively engage in voice (Appelbaum et al., 1999; Harley, 1999), the excerpts provided here suggest that an adequate epistemic status is also required; specifically, a status which is recognised by those the information is presented to. Since the employees generally take a low deontic stance relative to the management, both throughout the excerpts provided here and in the rest of the data set, holding a high epistemic status as an employee in relation to the work aspects being discussed may be a main resource in having one's voice heard. However, neither epistemic primacy nor the support of "experts" may be sufficient to secure that one's problem construction is heeded by the management and acted upon, as the analysis shows. Relatedly, we stipulate that wanting to avoid a direct rejection may be one reason why the employees in the four excerpts provided here often chose to present their suggestions in a mitigated way which did not strongly project an affiliative response from their line managers (see also Stevanovic, 2011).

On a final note, it seems relevant for further studies of interaction in participatory settings to consider how the participants' orientations to complainability shape their discussions and potentially the decisions that about future action. Besides how Finn strongly disaffiliated with the hearable moral aspect of the employees' negative evaluations of the work shoes in Excerpt 3, it could be argued that both Beth and Daniel in Excerpt 4 address the moral aspect of how the management has handled the employees' complaints by implying that relevant information about the employees' complaints is being dismissed or withheld. Insofar as the participants orient to the management as having potentially failed to demonstrate care for the employees' health and well-being, this would present another 
problem aspect to be negotiated in the interaction besides the more "technical" discussions of what causes a given problem to arise and how it can be solved (see, for example, Semmer et al., 2019). However, the analysis indicates that such matters are delicate and that it may be highly challenging to establish agreement around the employees' perspective in these types of settings.

\section{References}

Akkerman A, Sluiter R and Jansen G (2015) Direct and indirect employee participation. Luxembourg: Publications Office of the European Union. Available at: https://doi.org/10.2806/771155.

Angouri J and Bargiela-Chiappini F (2011) 'So what problems bother you and you are not speeding up your work?' Problem solving talk at work. Discourse \& Communication 5(3): 209-229. DOI: 10.1177/1750481311405589.

Appelbaum SH, Hébert D and Leroux S (1999) Empowerment: power, culture and leadership - a strategy or fad for the millennium? Journal of Workplace Learning 11(7): 233 254. DOI: $10.1108 / 13665629910291929$.

Asmuß B and Svennevig J (2009) Meeting Talk. An Introduction. Journal of Business Communication 46(1): 3-22.

Axley SR (1984) Managerial and organizational communication in terms of the conduit metaphor. Academy of Management Review 9(3): 428-437.

Baraldi C (2013) Forms of decision making: Gatekeeping and dialogic coordination in CISV organizational meetings. The Journal of Business Communication (1973) 50(4): 339361. Available at: http://journals.sagepub.com/doi/abs/10.1177/0021943613497055 (accessed 5 October 2017).

Boden D (1994) The Business of Talk. Organizations in Action. Cambridge: Polity.

Busck O, Knudsen H and Lind J (2010) The transformation of employee participation: Consequences for the work environment. Economic and Industrial Democracy 31(3): 285-305. DOI: 10.1177/0143831X09351212.

Clayman S and Heritage J (2014) Benefactors and beneficiaries: Benefactive status and stance in the management of offers and requests. Requesting in social interaction: 5586.

Clifton J (2009) Beyond Taxonomies of Influence. “Doing” Influence and Making Decisions in Management Team Meetings. Journal of Business Communication 46(1): 57-79. 
Cooke B and Kothari U (2001) The Case for Participation as Tyranny. In: Cooke B and Kothari U (eds) Participation: The New Tyranny? London: Zed Books.

Cooren F (2007) Interacting and Organizing. Analyses of a Management Meeting. Mahwah, NJ: Lawrence Erlbaum.

Craven A and Potter J (2010) Directives: Entitlement and contingency in action. Discourse Studies 12(4): 419-442.

Crow BK (1986) Conversational pragmatics in television talk: the discourse of Good Sex. Media, Culture and Society 8(4): 457-484.

Curl TS and Drew P (2008) Contingency and action: A comparison of two forms of requesting. Research on language and social interaction 41(2): 129-153.

Detert JR and Burris ER (2007) Leadership Behavior and Employee Voice: Is the Door Really Open? Academy of Management Journal 50(4): 869-884. DOI: http://dx.doi.org/10.5465/AMJ.2007.26279183.

Donaghey J, Cullinane N, Dundon T, et al. (2011) Reconceptualising employee silence: problems and prognosis. Work, Employment \& Society 25(1): 51-67. DOI: $10.1177 / 0950017010389239$.

Drew P and Heritage J (1992) Analyzing talk at work: An introduction. In: Drew P and Heritage J (eds) Talk at Work: Interaction in Institutional Settings. Cambridge, UK: Cambridge University Press, pp. 3-65.

Eurofound (2013) Work organisation and employee involvement in Europe. Luxembourg: Publications Office of the European Union. Available at: https://doi.org/10.2806/18346.

Farkas KR (2013) Power and access in the public hearings of city council meetings. Discourse \& Society 24(4): 399-420. Available at: http://journals.sagepub.com/doi/abs/10.1177/0957926513485750 (accessed 23 August 2017).

Francis D (1995) Negotiation, decision-making and formalism: The problem of form and substance in negotiation analysis. In: The Discourse of Business Negotiation. Berlin, Boston: De Gruyter Mouton.

Freeman RB (2007) Can the United States Clear the Market for Representation and Participation? In: Freeman RB, Boxall P, and Haynes P (eds) What Workers Say. Employee Voice in the Anglo-American Workplace. Ithaca: Cornell University Press.

Garner JT (2013) Dissenters, Managers, and Coworkers: The Process of Co-Constructing Organizational Dissent and Dissent Effectiveness. Management Communication Quarterly 27(3): 373-395. DOI: 10.1177/0893318913488946.

Hardy C and Leiba-O'Sullivan S (1998) The power behind empowerment: Implications for research and practice. Human Relations 51(4): 451-483. DOI: https://doi.org/10.1177/001872679805100402. 
Harley B (1999) The Myth of Empowerment: Work Organisation, Hierarchy and Employee Autonomy in Contemporary Australian Workplaces. Work, Employment \& Society 13(1): 41-66. DOI: 10.1177/09500179922117782.

Harley B (2014) High performance work systems and employee voice. In: Wilkinson A, Donaghey J, Dundon T, et al. (eds) Handbook of Research on Employee Voice. Northampton, MA: Edward Elgar Publishing.

Hasle P, Seim R and Refslund B (2016) From employee representation to problem-solving: Mainstreaming OHS management. Economic and Industrial Democracy. DOI: 10.1177/0143831X16653187.

Heery E (2015) Frames of reference and worker participation. In: Johnstone S and Ackers P (eds) Finding a Voice at Work? New Perspectives on Employment Relations. Oxford: Oxford University Press.

Hepburn A and Potter J (2011) Threats: Power, family mealtimes, and social influence. British Journal of Social Psychology 50(1): 99-120. DOI: 10.1348/014466610X500791.

Heritage $\mathbf{J}$ (2012) Epistemics in action: Action formation and territories of knowledge. Research on Language \& Social Interaction 45(1): 1-29.

Heritage J (2013) Epistemics in conversation. The handbook of conversation analysis: 370 394.

Heritage $\mathbf{J}$ and Raymond $\mathrm{G}$ (2005) The terms of agreement: Indexing epistemic authority and subordination in talk-in-interaction. Social psychology quarterly 68(1): 15-38.

Heritage J and Watson DR (1979) Formulations as conversational objects. Everyday language: Studies in ethnomethodology: 123-162.

Huisman M (2001) Decision-making in meetings as talk-in-interaction. International Studies of Management \& Organization 31(3): 69-90. DOI: https://doi.org/10.1080/00208825.2001.11656821.

Hutchby I (1996) Power in Discourse: The Case of Arguments on a British Talk Radio Show. Discourse \& Society 7(4): 481-497. DOI: 10.1177/0957926596007004003.

Jayyusi L (1984) Categorization and the Moral Order. Boston: Routledge \& Kegan Paul.

Jefferson G (2004) Glossary of transcript symbols with an introduction. Pragmatics and Beyond New Series 125: 13-34. DOI: 10.1075/pbns.125.02jef.

Johnstone S and Ackers P (2015) Finding a Voice at Work? New Perspectives on Employment Relations. Oxford, UK: Oxford University Press.

Kersley B, Alpin C, Forth J, et al. (2005) Inside the Workplace: First Findings from the 2004 Workplace Employment Relations Survey. London: DTI, ACAS, ESRC, PSI. 
Kitzinger C (2012) Repair. In: The Handbook of Conversation Analysis. Hoboken, NJ: John Wiley \& Sons, Ltd, pp. 229-256. DOI: 10.1002/9781118325001.ch12.

Landmark AMD, Gulbrandsen P and Svennevig J (2015) Whose decision? Negotiating epistemic and deontic rights in medical treatment decisions. Journal of Pragmatics 78: 54-69.

Larsson M (2017) Leadership in Interaction. The Routledge Companion to Leadership.

Lindwall O, Lymer G and Ivarsson J (2016) Epistemic status and the recognizability of social actions. Discourse Studies 18(5): 500-525. Available at: http://journals.sagepub.com/doi/abs/10.1177/1461445616657958 (accessed 9 October 2017).

Madill A, Widdicombe S and Barkham M (2001) The Potential of Conversation Analysis for Psychotherapy Research. The Counseling Psychologist 29(3): 413-434. DOI: 10.1177/0011000001293006.

Marchington M and Wilkinson A (2005) Direct Participation and Involvement. In: Bach S (ed.) Managing Human Resources: Personnel Management in Transition. Oxford: Blackwell, pp. 398-423.

Markey R and Knudsen H (2014) Employee participation and quality of work environment: Denmark and New Zealand. International Journal of Comparative Labour Law and Industrial Relations 30(1): 105-126. Available at: http://www.kluwerlawonline.com/abstract.php?area=Journals\&id=IJCL2014007 (accessed 4 October 2017).

Mondada L (2013) Displaying, contesting and negotiating epistemic authority in social interaction: Descriptions and questions in guided visits. Discourse Studies 15(5): 597626.

Morrison EW (2011) Employee Voice Behavior: Integration and Directions for Future Research. The Academy of Management Annals 5(1): 373-412. DOI: https://doi.org/10.1080/19416520.2011.574506.

Nielsen KM, Randall R, Holten A-L, et al. (2010) Conducting organizational-level occupational health interventions: What works? Work \& Stress 24(3): 234-259. DOI: 10.1080/02678373.2010.515393.

Parent-Thirion A, Biletta I, Cabrita J, et al. (2017) 6th European Working Conditions Survey: Overview Report. 2017 update. EF 16/34. Luxembourg: Publications Office of the European Union.

Pomerantz A (1984) Agreeing and disagreeing with assessments: some features of preferred/dispreferred turn shapes. In: Atkinson JM and Heritage J (eds) Structures of Social Action: Studies in Conversations Analysis. Cambridge: Cambridge University Press. 
Raymond G and Heritage J (2006) The epistemics of social relations: Owning grandchildren. Language in society 35(05): 677-705. DOI:

http://doi.org/10.1017/S0047404506060325.

Sacks H (1992) Lectures on Conversation. Oxford: Blackwell Publishers.

Sacks H, Schegloff EA and Jefferson G (1974) A simplest systematics for the organization of turn-taking for conversation. language: 696-735.

Samra-Fredericks D (2010) Ethnomethodology and the moral accountability of interaction: Navigating the conceptual terrain of 'face' and face-work. Journal of Pragmatics 42(8): 2147-2157.

Schegloff EA (2005) On Complainability. Social Problems 52(4): 449-476. DOI: 10.1525/sp.2005.52.4.449.

Schuler D and Namioka A (1993) Participatory Design: Principles and Practices. CRC Press.

Semmer NK, Tschan F, Jacobshagen N, et al. (2019) Stress as Offense to Self: a Promising Approach Comes of Age. Occupational Health Science. DOI: 10.1007/s41542-01900041-5.

Stevanovic M (2011) Participants' Deontic Rights and Action Formation: The Case of Declarative Requests for Action. Interaction and Linguistic Structures (InLiSt) (52): 38. Available at: http://www.inlist.uni-bayreuth.de/issues/52/Inlist52.pdf.

Stevanovic M (2012) Establishing joint decisions in a dyad. Discourse Studies 14(6): 779803. DOI: $10.1177 / 1461445612456654$.

Stevanovic M and Peräkylä A (2014) Three orders in the organization of human action: On the interface between knowledge, power, and emotion in interaction and social relations. Language in Society 43(02): 185-207.

Stevanovic M and Svennevig J (2015) Introduction: Epistemics and deontics in conversational directives. Journal of Pragmatics 78: 1-6. DOI: 10.1016/j.pragma.2015.01.008.

Stivers T and Sidnell J (eds) (2012) The Handbook of Conversation Analysis. Hoboken, NJ: John Wiley \& Sons.

Stivers T, Mondada L and Steensig J (2011) Knowledge, morality and affiliation in social interaction. In: Stivers T, Mondada L, and Steensig J (eds) The Morality of Knowledge in Conversation. Cambridge, UK: Cambridge University Press, pp. 3-24.

Stokoe E (2011) Simulated Interaction and Communication Skills Training: The 'Conversation-Analytic Role-Play Method'. In: Antaki C (ed.) Applied Conversation Analysis. London: Palgrave Macmillan UK, pp. 119-139. DOI:

10.1057/9780230316874_7. 
Svennevig J (2011) Leadership style in managers' feedback in meetings. In: Angouri J and Marra M (eds) Constructing Identities at Work. London: Palgrave Macmillan, pp. 1739.

von Thiele Schwarz U, Nielsen KM, Stenfors-Hayes T, et al. (2017) Using kaizen to improve employee well-being: Results from two organizational intervention studies. Human Relations 70(8): 966-993. DOI: 10.1177/0018726716677071.

\section{Transcription legend}

(2.5) A pause of 2.5 seconds

(.) Very short pause

「1 Overlap, top section

【」 Overlap, bottom section

[ ] Unhearable (text in brackets indicates a guess)

- Utterance is spoken at a low volume

$=\quad$ Latching speech

$>\quad$ Enclosed utterance is at a higher pace

: $\quad$ Sound is elongated

.h Inbreath ("h" indicates hearable outbreath)

- $\quad$ Speech is cut off

(( )) Anonymized, or transcriber's comment

? Upward intonation

Table 1. Participants in the excerpts and their formal work roles

\begin{tabular}{|l|l|l|l|}
\hline Excerpt 1-3 & & Excerpt 4 & \\
\hline$\underline{\text { Name }}$ & $\underline{\text { Role }}$ & $\underline{\underline{N a m e}}$ & $\underline{\underline{\text { Role }}}$ \\
\hline Amelia & Meeting facilitator & Beth & $\begin{array}{l}\text { Employee (elected as the } \\
\text { employees' health and safety } \\
\text { representative) }\end{array}$ \\
\hline Arthur & Employee & Daniel & Employee \\
\hline Finn & Line manager & Katie & Employee \\
\hline Max & Employee & Tim & Line manager \\
\hline Noah & Employee & & \\
\hline Oliver & Employee & & \\
\hline
\end{tabular}




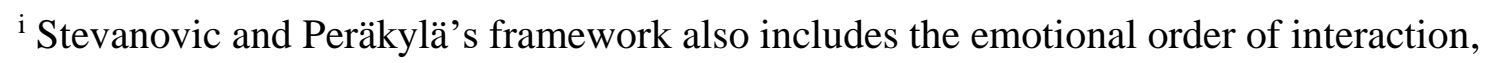
however, we have chosen to focus on the epistemic and deontic orders and their interplay in this article.

ii This feature of our data seemed to parallel how problem formulations are also described as a key topic of discussion in other "therapeutic" contexts, such as psychotherapy (Madill et al., 2001), sex therapy (Crow, 1986) and neighbourhood mediation (Stokoe, 2011).

iii The fact that most meetings had 6-8 employees seated at the table means that short utterances or utterances with a low volume in some cases cannot be attributed confidently to one speaker. These utterances are marked as “M.E.?" or "F.E.?” for unidentified male or female employee. 